\title{
Anabases
}

ANABASES Traditions et réceptions de l'Antiquité

22 | 2015

Varia

\section{Antiquités parallèles (3) Judas, collabo ou résistant ?}

Claude Aziza

\section{OpenEdition}

Journals

Édition électronique

URL : http://journals.openedition.org/anabases/5498

DOI : 10.4000/anabases.5498

ISSN : 2256-9421

Éditeur

E.R.A.S.M.E.

\section{Édition imprimée}

Date de publication : 20 octobre 2015

Pagination : 217-221

ISSN : 1774-4296

\section{Référence électronique}

Claude Aziza, «Antiquités parallèles (3) Judas, collabo ou résistant ? », Anabases [En ligne], 22 | 2015, mis en ligne le 20 octobre 2018, consulté le 21 octobre 2019. URL : http://journals.openedition.org/ anabases/5498; DOI : 10.4000/anabases.5498

(c) Anabases 


\section{Antiquités parallèles (3) Judas, collabo ou résistant?}

Claude AzızA

A u moment où vous lirez ces lignes, vous aurez sans doute entre les mains le DvD d'un film que vous n'aurez pas manqué d'avoir vu: Histoire de Judas, de Rabah Ameur-Zaïmeche, le réalisateur des Chants de Mandrin (20II). “Enfant, dit-il, j'avais deux héros: Mandrin et Jésus. Ce sont deux figures fondatrices sur lesquelles je me suis construit»(Le Monde, 8 avril 2or5). Et il ajoute, ce qui ne laissera pas de surprendre: “À mes yeux, il (Judas) porte le plus beau prénom du monde. Littéralement, il signifie "Je suis Juif”, "Je suis l'autre” » (ibid.). Réhabilitation donc de Judas, au nom d'un œcuménisme qu'on ne peut que louer chez cet Algérien, né en I966, issu d'une tribu berbère, de ces «Berbères qui, avant d'être islamisés, ont dû être animistes, juifs, chrétiens et donatistes » (ibid.). Le réalisateur condamne dans la même rencontre «le nouvel antisémitisme [...] (qui) n’a rien à voir avec l'antisémitisme chrétien. „ Le film, tourné dans l'Est algérien, dans la région de Biskra et dans les Aurès, se veut le fruit de vastes lectures fictionnelles et historiques, qui sont présentées, un peu naïvement, il faut bien l'avouer, comme de longues recherches. Certes le réalisateur et sa scénariste ont cédé - comme tant d'autres - à la tentation de trouver du nouveau et de donner une autre lecture des Évangiles, mais on leur pardonnera aisément. Tant les droits de l'imagination les autorisent à voir en Judas le fidèle gardien des paroles d'un jeune rabbi de Nazareth. Mais quelle image donne de Judas la fiction? Une enquête sur la fortune du personnage.

Le malheureux hasard d'une paronomase a créé la confusion. En latin, un Juif se dit Judaeus. Et, de Judas à Judaeus, il n'y a qu'un pas. Pourtant on ne le franchira pas aisément. Rien dans les premiers textes qui fasse de Judas autre chose qu'un disciple qui a trahi. Rien ou presque chez les Apologistes. Justin n'en souffle mot, alors qu'il mentionne dans son Apologie ( II $^{\mathrm{e}}$ siècle) que Juda, fils de Jacob, est 
l'ancêtre de la tribu d'Israël qui porte son nom. Le moment était pourtant propice pour parler du traître. C'est Tertullien le premier qui parle de «l'apôtre apostat» (Sur les hérésies, II, 5).

Il faudra attendre la fin du $\mathrm{III}^{\mathrm{e}}$ siècle pour lire dans le Contre les Juifs du PseudoCyprien que les Juifs aiment Judas. Juvencus, un poète du $\mathrm{Iv}^{\mathrm{e}}$ siècle, insiste sur l'assimilation avec le plus d'outrance: Judas le traître, Judas le furieux, Judas est un Juif ordinaire qui personnifie l'ensemble des Juifs. Le thème est lancé; il aura un succès fou. On n'en suivra pas ici les avatars tout au long des siècles mais on ne peut s'empêcher d'admirer la remarquable plasticité du mythe qui prend forme dans La Légende dorée. Dans le célèbre texte du xıI ${ }^{\mathrm{e}}$ siècle de Jacques de Voragine (disponible en deux tomes chez Garnier-Flammarion, n 132 et i33), l'histoire de Judas, qui se croise avec celle de Pilate, reprend des éléments tirés des légendes de Moïse (l'abandon d'un enfant au fil de l'eau), de Romulus et Remus (le fratricide) et d'Edipe (l'inceste et le parricide)! Le seul Juif qui apparaisse, individualisé, dans les Mystères du Moyen Âge, c'est Judas, figure caricaturale et stéréotypée du traître.

Si Judas, dans la littérature moderne, apparaît généralement - avec des teintes différentes - dans les récits consacrés à Jésus, il a été, pourtant, jugé digne de devenir un héros de roman. Sa réhabilitation - qui suit avec des nuances celle du Juif Errant au siècle romantique - commence sans doute avec l'essai de Thomas de Quincey: Judas Iscariote (I853, Éditions Ombres, I99o, “Bibliothèque Ombres », 200I).

Dès la fin du XIX ${ }^{\mathrm{e}}$ siècle l'Italien E. Petrucelli De La Gatina, qui écrit en français, en fait dans ses Mémoires de Judas (I867) un patriote déçu par l'action de Jésus. Telle est aussi la thèse de l'Israélien Igal Mossinsohn: dans Judas (I963, TR Calmann-Lévy, I965), il montre, avec originalité, un patriote déçu qui a obéi à son chef et qui, dix ans après, réfugié dans une île grecque, apprend ce que la tradition évangélique raconte de lui. Pour Félicien Champsaur (Le Crucifié, Ferenczi, I93o), Frank Slaughter (La Magdaléenne, TR Presses Pocket, I952) et Nikos Kazantzaki (La Dernière Tentation, TR Presses Pocket, I959), c’est un zélote.

Au contraire, le Judas de l’Américain Eric Linklater (I939, TR éd. de Visscher, Bruxelles, I946) n'aspire qu'à la paix: il voit en Jésus un dangereux révolutionnaire. Le Judas Iscariote du Russe L. Nikolaïevitch Andreev (I907) désire passionnément, maladivement, être aimé et admiré. Il est assez semblable à celui d'Albert Malaurie, qui donne, dans La Femme de Judas (Grasset, I924), la parole - ce qui est rare - à son épouse. Le Judas de Lanza Del Vasto (Grasset, I938) oriente le lecteur dans une semblable direction: déçu par amour, l'apôtre trahit celui qui ne l'a pas aimé comme il l'aurait voulu. Le Judas de Charles-Henry Hirsch (L'Apôtre Judas, ig36, Mercure de France) a fait ce qu'il a fait par amour de Jésus et pour que s'accomplisse son message. 
Plus proches de nous, et donc plus accessibles, quelques beaux romans ont tenté de mieux comprendre. Dans Le Sel de la terre (I965, TR Denoël, ı965), l’Italien Carlo Monterosso voit en Judas un révolutionnaire énergique qui se débarrasse, avec l'accord de ses compagnons, d'un chef jugé trop timoré. Avec une intuition que les exégèses actuelles font ressortir, Robert Morel et Guiseppe Berto, un Français et un Italien, qui écrivent chacun un Évangile selon Judas (Julliard, I946; I978, TR Denoël, I982), replacent la figure du traître dans une perspective théologique et en font presque celui par qui le salut arrive, puisqu'il a causé la mort de Jésus... Traître, certes, pour Jean Ferniot, dans Saint Judas (Grasset, I982) - un titre volontairement provocateur - mais par devoir et par amour. Bref, le premier martyr...

Plus humain, le Judas de Pierre Bourgeade (Mémoires de Judas, Gallimard, i985) qui voit en lui le symbole de l'homme moderne dont l'ambivalence vis-à-vis du sacré en fait la tragique grandeur. Une sorte de double de Jésus.

Une des dernières approches du personnage cède assez volontiers à la mode des romans historiques à tendance policière. Dans Judas Iscariote (Actes Sud, I993), Dominique Reznikoff fait de Judas un policier du Temple chargé de suivre et d'espionner un nommé Jésus. Captivé par son message, il va tenter de le sauver mais sera trahi par ses employeurs. Il est donc innocent.

La “découverte» de L'Évangile de Judas en 2005 (voir la traduction intégrale et commentée de L'Évangile de Judas, Flammarion, 2006) a relancé de fumeuses spéculations. Gérald Messadié, un des spécialistes du genre, dans Judas le bienaimé (J.C.Lattès, 2007, Le Livre de poche, n³ir66) tente de démontrer que Judas était en fait le seul qui ait vraiment compris et aimé Jésus. Jean-Yves Leloup, dans Un homme a trahi (Albin Michel, 2006), voit en Jésus et Judas les deux faces d'une unique Révélation: le Mal face au Bien. Jacques Duchesne, dans Judas. Le deuxième jour (Plon, 2007), met l'accent sur le débat que les disciples de Jésus ont dû nécessairement entamer le lendemain de la crucifixion sur le rôle de Judas. Traître ou complice? Christian Karlson Stead imagine que Judas a écrit ses mémoires. Il est resté tout le temps fidèle à Jésus (Mon nom était Judas, 2006, TR Citadelle, 2007). On préfèrera cependant l'intuition d'Hubert Prolongeau qui, dès 2004, dans Le Baiser de Judas (Grasset, Le Livre de poche, n³o6go), avait avancé des conclusions que L'Évangile de Judas validait implicitement l'année suivante, à savoir que Judas, résistant actif, avait été fidèle à Jésus jusqu’à sa mort.

Loin des Évangiles, le roman méconnu de Leo Perutz, Le Judas de Léonard (I959, TR Phébus, I987), imagine que Léonard de Vinci, en I498, cherche un modèle pour le Judas qui figure sur sa Cène. Magnifique roman sur les figures modernes que peut prendre Judas.

Lorsqu'il s'empare du personnage, le théâtre lui confère une épaisseur scénique. Le Judas de P.Raynal dans A souffert sous Ponce Pilate (Stock, I939) est " un être extrêmement borné, une petite tête [...] un petit paysan, naïf, rêveur, futé, bavard ». Dans Un nommé Judas (L’Avant-scène théâtre, n 96, ı954), Claude-André 
Puget et Pierre Bost font du traître un personnage presque existentialiste et nihiliste qui veut infléchir le destin. Il est fort différent du Judas de Marcel Pagnol (Presses Pocket, I955, n I705) qui, lui, reprend le thème de la prédestination et présente son héros comme une victime.

Et le cinéma? Friand de vies de Jésus, il n'a consacré que peu de films à Judas, aujourd'hui invisibles: Le Baiser de Judas (Armand Bour, Igo8), une production française académique du Film d'Art, tout comme, en ıgı, Guida d'Arrigo Frustra. En ıgı, le Guida de Febo Mari est amoureux de Marie-Madeleine et la jalousie le fait livrer Jésus. Humain, trop humain! Dans le grotesque Golgotha (Julien Duvivier, I935, DVD), Judas devient un traître de comédie, interprété par l'ineffable Lucas Gridoux.

On en signalera encore trois, pouvant être vus au hasard de rétrospectives. Si El beso de Judas (Rafael Gil, ig53) reprend, au temps du franquisme, l'histoire traditionnelle, Ignacio F. Iguino et Jules Dassin ont réalisé deux films curieusement semblables à quelques années d'écart. ElJudas (1952) et Celui qui doit mourir (1956) se passent lors d'une reconstitution de la Passion, ici dans la Grèce occupée par les Turcs, là, à Esperraguerra, en Catalogne. On devine que l'homme chargé de jouer Judas se comportera comme lui dans la réalité. On ne sera donc pas surpris de voir, chez Dassin, Judas-Roger-Navarro-Hanin vendre son compatriote patriote JésusPierre Vaneck aux autorités ottomanes! En I989, Judas passe à la tv dans Il bacio di Giuda de Paolo Benvenutti.

Rabattons-nous plutôt sur quelques vies de Jésus où Judas ne manque pas d'épaisseur. On peut hésiter entre le Judas révolutionnaire de La Dernière Tentation du Christ (Martin Scorcese, I988, DvD, d'après le roman homonyme de Kazantzaki), le Judas noir du très sulfureux film musical de Norman Jewinson: Jésus superstar, I973, DVD), le doublet de Judas en la personne du scribe Zira dans le très (trop?) académique Jésus de Nazareth de Franco Zeffirelli (I977, DVD). Mais le Judas le plus intéressant on le trouvera dans un film d'où... il est absent: Jésus de Montréal (I989, DVD). Le réalisateur Denys Arcand a réussi le tour de force de montrer Judas sous les traits du prêtre qui demande une Passion à une troupe de comédiens pour les trahir ensuite et causer indirectement la mort de celui qui interprète le rôle de Jésus...

Dans les Vies de Jésus en BD, le plus souvent très conformistes, le personnage est représenté comme le veut la tradition. Mais, parfois, comme dans La Bible: Jésus de Nazareth (Larousse, I984), d'une façon inacceptable, caricaturé graphiquement dans une perspective que l'on pensait à jamais disparue! Seule La Bible: Nouveau Testament (Le Sarment, I980) montre un Judas déçu politiquement par Jésus. 
Que de Judas! Y compris, dans la chanson populaire, comme Judas, chantée par Lucienne Delyle (I953, disponible sur YouTube), dont je ne résiste pas à vous donner de savoureux extraits :

J. «Judas, tout comme Judas, tu as vécu près de moi en cachant/au fond de toi la trahison et la haine/ Baisers, baisers de Judas/Ta lèvre donne un frisson dissimulant le poison/ Poison dont ton âme est pleine. » $\mathbb{J}$

Sans oublier les Inconnus qui, dans Jésus II. Le retour (I99o, disponible sur YouTube et en DVD), nous montrent, face à un Judas sans appétit, le soir du repas pascal, un Jésus qui lui demande: “Tu trouves que ce que tu as dans ton assiette n'est pas très catholique? „ De la nourriture à la boisson il n'y a qu'un pichet de la nouvelle bière belge brassée, Judas, lancée à l'occasion des Pâques de i987. Boisson traître, on s'en doute...

\section{Claude Aziza}

Université de la Sorbonne Nouvelle, Paris III 6, Square de Port-Royal, 75013 Paris

claude.aziza@laposte.net 